ORIGINAL ARTICLE

\title{
Chronic obstructive pulmonary disease among residents of an historically industrialised area
}

\author{
Anthony C Darby, ${ }^{1}$ Judith C Waterhouse, ${ }^{2,3}$ Vivien Stevens, ${ }^{4}$ Clare G Billings, ${ }^{3}$ \\ Catherine G Billings, ${ }^{2,3}$ Clare M Burton, ${ }^{1}$ Charlotte Young, ${ }^{5}$ Jeremy Wight, ${ }^{6}$ \\ Paul D Blanc, ${ }^{7}$ David Fishwick ${ }^{1}$
}

\begin{abstract}
- Additional materials are published online only. To view these files please visit the journal online (http://dx.doi.org/ 10.1136/thoraxjnl-2011200543).

${ }^{1}$ Centre for Workplace Health, Health and Safety Laboratory, Buxton, UK

${ }^{2}$ Centre for Workplace Health, University of Sheffield, UK

${ }^{3}$ Respiratory Function Unit, Royal Hallamshire Hospital, Sheffield, UK

${ }^{4}$ Scientific Computing and Informatics, Medical Imaging and Medical Physics, Royal Hallamshire Hospital, Sheffield, UK

${ }^{5}$ Mathematical Sciences Unit, Health and Safety Laboratory, Buxton, UK

${ }^{6}$ Sheffield NHS Primary Care Trust, Sheffield, UK

${ }^{7}$ Department of Medicine, University of California, San Francisco, USA
\end{abstract}

\section{Correspondence to}

Dr Anthony Darby, Centre for Workplace Health, Health and Safety Laboratory, Buxton SK17 9JN, UK;

anthony.darby@nhs.net

Received 30 June 2011 Accepted 11 April 2012

Published Online First 28 June 2012

\section{ABSTRACT}

Objective To assess the contribution of workplace exposures to chronic obstructive pulmonary disease (COPD) risk in a community with a heavy burden of past industrial employment.

Methods A random population sample of Sheffield, UK residents aged over 55 years $(n=4000)$, enriched with a hospital-based supplemental sample $(n=209)$, was approached for study. A comprehensive self-completed questionnaire elicited physician-made diagnoses, current symptoms, and past workplace exposures. The latter were defined in three ways: self-reported exposure to vapours, gases, dusts and fumes (VGDF); response to a specific exposure checklist; and through a job exposure matrix (JEM) assigning exposure risk likelihood based on job history independent of respondent-reported exposure. A subset of the study group underwent lung function testing. Population attributable risk fractions (PAR\%), adjusted for age, sex and smoking, were calculated for association between workplace exposure and COPD.

Results 2001 (50\%) questionnaires were returned from the general population sample and $60(29 \%)$ by the hospital supplement. Among 1754 with complete occupational data, any past occupational exposure to VGDF carried an adjusted excess risk for report of a physician's diagnosis of COPD, emphysema, or chronic bronchitis (ORs 3.9; 95\% Cl 2.7 to 5.8), with a corresponding PAR\% value of $58.7 \%(95 \% \mathrm{Cl} 45.6 \%$ to 68.7\%). The PAR\% estimate based on JEM exposure was $31 \%$. From within the subgroup of 571 that underwent lung function testing, VGDF exposure was associated with a PAR\% of $20.0 \%(95 \% \mathrm{Cl}-7.2$ to $40.3 \%$ ) for Global initiative for chronic Obstructive Lung Disease (GOLD) 1 (or greater) level of COPD.

Conclusion This heavy industrial community-based population study has confirmed significant associations between reported COPD and both generic VGDF and JEM-defined exposures. This study supports the predominantly international evidence-based notion that workplace conditions are important when considering the current and future respiratory health of the workforce.

\section{INTRODUCTION}

Chronic obstructive pulmonary disease (COPD) is a common disease, associated with substantial morbidity, mortality, direct and indirect healthcare costs, including COPD-related absence from work. ${ }^{1-7}$ While the primary contributor to COPD

\section{Key messages}

What is the key question?

- To what extent does occupation contribute to chronic obstructive pulmonary disease (COPD) causation in an industrialised area of the UK.

What is the bottom line?

- In this population-based study, a significant association was found between COPD and previous occupational exposures.

\section{Why read on?}

- As a cause of significant morbidity and mortality, all contributing factors to COPD causation should be considered.

risk overall is tobacco smoking, other important causes are also recognised, including harmful occupational and environmental exposures. ${ }^{8}$ Indeed, the 'cause' of COPD is likely to be multifactorial in many cases, reflecting complex exposure-host interactions. Thus, a more comprehensive understanding of the relative contribution to COPD causation from occupational exposures offers an important platform on which to construct targeted and effective interventions to reduce the burden of disease.

The role of occupational exposures in the development of COPD (including chronic bronchitis) has long been identified; landmark reports from the nineteenth century explored this relationship. ${ }^{9-11}$ This concept was developed further in the twentieth century, with research establishing a link between dusty work and the development of chronic bronchitis ${ }^{12}$ and consolidating the view that occupational exposures were an important risk factor for developing obstructive airway disease. ${ }^{13}$ Many more recent studies have also identified that workplace exposures to vapours, gases, dusts and fumes (VGDF) are potentially harmful to lung health and contribute to the overall burden of COPD. ${ }^{14-17}$ These workplace-based exposures have also been shown to interact with tobacco exposure, in certain studies increasing risk to a degree that may be more than simply additive. ${ }^{14} 15$

Consistent estimates place the size of this occupational contribution to COPD at approximately $15 \%$ of the total burden of the disease. ${ }^{18}{ }^{19}$ Even though this estimate varies among individual 
studies, this figure gives a broad sense of the future COPD burden that might be avoidable were all harmful occupational exposures removed. This represents an important public health issue, with the future possibility to reduce incident cases, and potentially, to slow progression in those with already established COPD.

Very few modern analyses have examined UK populations. ${ }^{20}$ We therefore describe the results of an epidemiological study to assess this contribution, based in Sheffield, UK.

\section{METHODS}

\section{Initial questionnaire phase}

A random population sample of 4000 Sheffield residents, aged over 55 (with no upper age limit or specific exclusion criteria), was identified from health records in a specific area within the city. In multiple waves over a 12-month period, postal questionnaires were sent to potential participants covering demographics, health, and occupational history, including work exposures. Work exposure was categorised in three ways: based on exposure to vapours, gas, dust, or fumes, exposure to a checklist of specific exposures, and lastly, by assignment of exposure likelihood to COPD-causing agents based on a job exposure matrix (JEM) independent of the respondent's self-reported exposures. Social deprivation was assessed based on the proportion of individuals within a participant's post (zip) code receiving income support (\%IS).

\section{Airway disease case definition and follow-up assessment}

'Probable' cases of airway disease required report of a physician's diagnosis of COPD (including emphysema or chronic bronchitis) or asthma or, alternatively, Medical Research Council ${ }^{21}$ grade 3 dyspnoea and another respiratory symptom (wheeze, chest tightness, winter cough/phlegm). 'Possible' cases lacked a physician's diagnosis but reported dyspnoea or respiratory symptoms. We retained such possible cases in the 'No reported diagnosis group' and did not analyse them separately, but did use this as a basis of exclusion for recruitment for spirometry. Thus, only probable cases and those without symptoms or a diagnosis (referents) were recruited for home-based spirometric assessment, with an option for testing at a hospital-based lung function laboratory.

\section{Supplemental cases}

We enriched the study population with additional cases of COPD ( $n=209)$ assessed at the same hospital-based lung function laboratory that the population-based sample had the option of attending in lieu of home visit spirometry. These participants completed the same questionnaire as noted above.

\section{Data analysis}

We used logistic regression analysis to test the associations among smoking, occupational exposures and COPD by calculating Odds Ratios (OR) unadjusted and adjusted for age, sex and smoking. We defined COPD based on self-reported COPD, emphysema or chronic bronchitis (then repeated these excluding bronchitis alone). Separate analyses were conducted on the subpopulation with lung function, COPD being defined according to the Global initiative for chronic Obstructive Lung Disease (GOLD) criteria. ${ }^{1}$ We derived population attributable risk fractions (PAR\%) estimates and their 95\% CIs from adjusted ORs.

Additional details of study methods are provided in an online supplement.

\section{RESULTS}

A total of 2001 (50\%) of 4000 questionnaires were returned from the random population sample, 1587 (39.7\%) from the first mail out, and a further 414 (10.4\%) from the second. The 50\% response rate is conservative, as the non-responders include at least 260 known by the second mailing to have moved or to have died and 95 others were otherwise determined to be non-eligible (together indicating a minimum response rate of $55 \%$ among the eligible).

Despite the obvious absence of clinical data for non-responders from the population sample, age, gender, and deprivation data were available. Responders (mean age at randomisation 68.5, SD 8.8) were significantly younger $(p<0.001)$ than the 1999 nonresponders (69.9, SD 10.0). There was no statistically significant difference by gender; responders had significantly less $(p<0.001)$ social deprivation: responders \%IS of $20.5 \%$ (SD 16.8) compared with non-responders (25.7\%, SD 18.2).

Sixty (29\%) of the 209 patients in the supplemental sample participated. As cases were identified from their physiology request card prior to attendance, reasons for non-inclusion were varied and included non-attendance or refusal. Figure 1 shows a more detailed breakdown of the study numbers within each COPD group.

Of the total 2061 (population and enriched) participants, 1579 reported no doctor's diagnosis of chronic airway disease. Of the remaining, 119 (5.8\%) reported a doctor's diagnosis of COPD, 50 of whom also reported concomitant asthma. Eighty-three (4.0\%) reported emphysema and 123 (6.0\%) chronic bronchitis. Table 1 presents demographics, smoking and symptom reporting data by reported diagnosis.

Table 2 provides a detailed occupational exposure profile, including JEM-derived exposure risk assignments, across the main diagnostic categories. Excluding those with missing or insufficient occupational or smoking data, 1798 participants remained for this analysis. Significant differences are present among the diagnostic groups for self-reported and JEM-derived exposure assessment. Comparing self-reported VGDF exposure and JEM estimates, $75.9 \%$ of those who reported ever having VGDF exposure received a JEM rating compatible with workplaced exposures of high or intermediate COPD risk.

Table 3 presents the ORs and PAR\% values relating occupational exposures and smoking to COPD. Ever exposure to VGDF was associated with an excess risk of COPD with ORs of 3.7 and 3.9 (with or without the exclusion of chronic bronchitis in the COPD definition, respectively) following adjustment for age, sex and smoking (corresponding PAR\% values of 57.6 and $58.7 \%$ ). A separate sensitivity analysis, excluding all those with concomitant asthma from the any COPD category, yielded a PAR\% of $60.4 \%$. The JEM-associated PAR\% (combining intermediate and high-likelihood exposure jobs) was $30.8 \%$ for broadly defined COPD. Excluding chronic bronchitis, this estimate was $12.1 \%$ (discounting intermediate JEM risk which was not statistically significant).

The smoking-associated PAR\% estimates adjusted for VDGF and demographics were $44.7 \%$ and $52.8 \%$ for any COPD and any COPD excluding chronic bronchitis alone, respectively. Adjusting for JEM instead of VGDF, slightly higher smokingassociated PAR\% values were obtained, as shown in table 3.

Certain differences emerged in sex-stratified analyses. For example, using the broader any COPD definition, the effect of VGDF-associated PAR\% for men was estimated to be $59.3 \%$, while for women it was $50.0 \%$.

In addition to broadly defined VGDF exposure, adjusted ORs also manifested an excess risk for any COPD for the majority of the specific occupational exposures analysed. ORs of 2.0 or greater were identified for: cadmium fumes, batteries or silver solder ( $\mathrm{n}$ exposed=66, OR 2.8, 95\% CI 1.5 to 5.1); incinerators, 


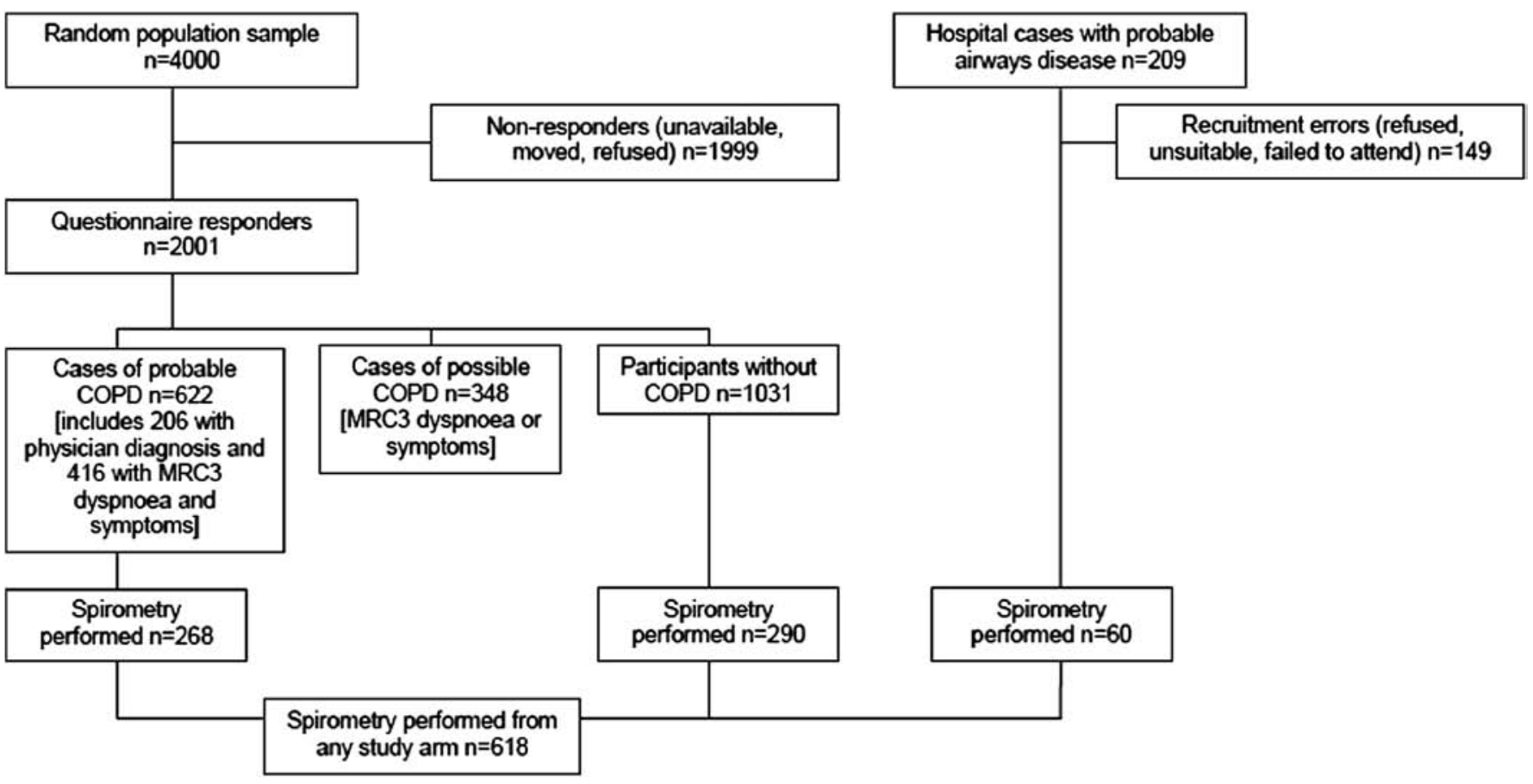

Figure 1 Subject sampling schematic. COPD, chronic obstructive pulmonary disease; MRC3, Medical Research Council grade 3 shortness of breath.

boilers or oil refineries (n exposed=118, OR $2.395 \%$, CI 1.4 to 3.6); irritant gases, for example, chlorine or ammonia (n exposed=147, OR 2.1, 95\% CI 1.4 to 3.3); coal dust or powder (n exposed=197, OR $2.095 \%$, CI 1.3 to 2.9); wheat, flour or other grain dusts (n exposed=99, OR 2.0,95\% CI 1.2 to 3.4 ) and wood dust or sawdust (n exposed=168, OR 2.0, 95\% CI 1.3 to 3.1). The more broadly defined exposure categories of organic dust (OR 2.0), inorganic dust (OR 2.5), and combustion by-products (OR 1.4) also were each associated with significantly $(p<0.05)$ increased odds of any COPD. Steel industry work increased the odds of any COPD by $25 \%$ (OR 1.26 ; $95 \%$ CI 0.9 to 1.7 ); and although this was not statistically significant, the frequency of this occupation in the study population yielded a PAR\% of $10.2 \%$ (95\% CI $-4.5 \%$ to $22.8 \%$ ).

A further analysis was carried out excluding the enriched population from the dataset. Again, the association between any COPD and VGDF exposure retained its significance (OR 4.1, $95 \%$ CI 2.7 to 6.3). Very similar results were observed for any COPD excluding chronic bronchitis alone. Further adjusted supplementary analysis using \%IS as a continuous variable in the VGDF and any COPD analysis identified \%IS to be a significant independent predictor of disease $(p<0.0001)$, but its

Table 1 Demographic, smoking and symptom reporting data by predominant airway diagnosis among 2061 participants

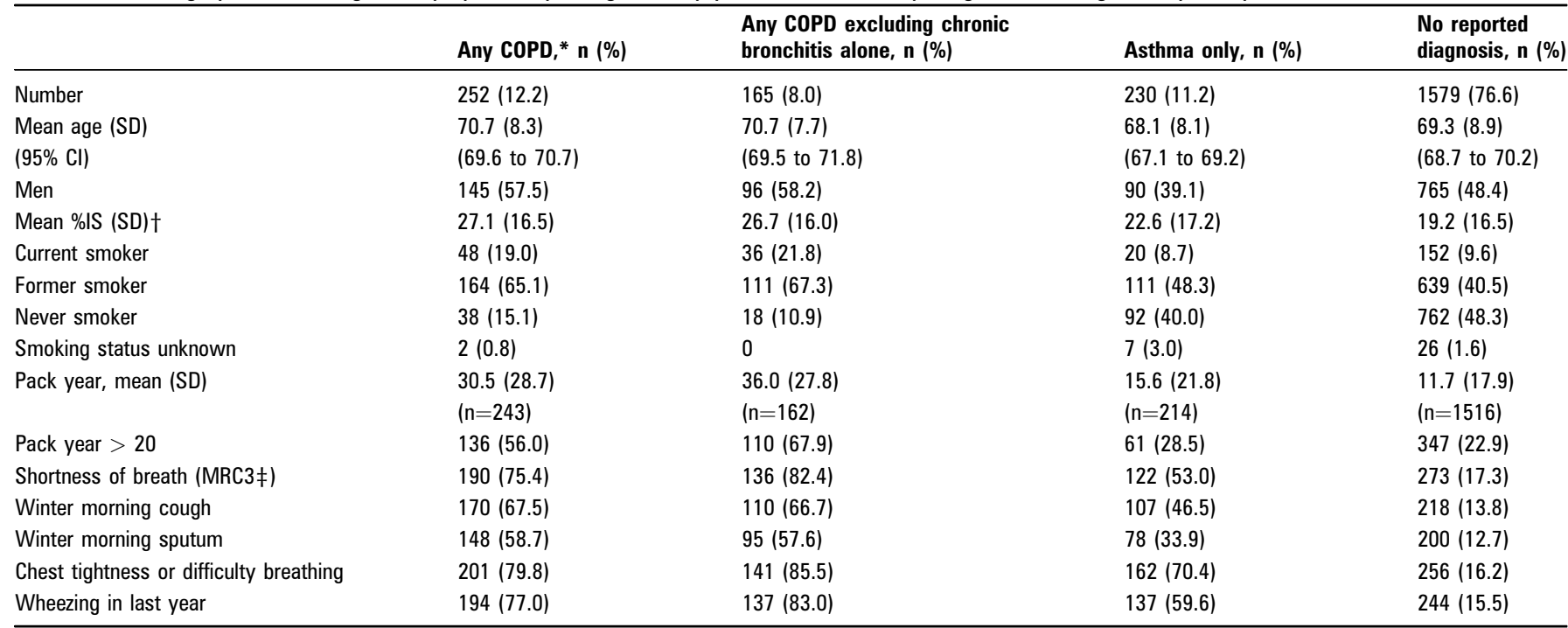

The differences among the categories are statistically significant $(\mathrm{p}<0.05)$ in three-way comparisons (among any chronic obstructive pulmonary disease (COPD) (or any COPD excluding chronic bronchitis), asthma, and no reported diagnosis).

*COPD or emphysema or chronic bronchitis, and may include concomitant asthma.

†Missing data for mean \% Income Support (\%IS), $n=132$, distributed similarly across all groups.

$\neq$ Medical Research Council grade 3 shortness of breath. 
Table 2 Occupational factors by predominant diagnosis among 1798 participants with complete occupational and smoking data

\begin{tabular}{|c|c|c|c|}
\hline & $\begin{array}{l}\text { Any COPD*, } \\
\text { n (\% exposed) }\end{array}$ & $\begin{array}{l}\text { Asthma only, } \\
\text { n (\% exposed) }\end{array}$ & $\begin{array}{l}\text { No reported diagnosis, } \\
\text { n (\% exposed) }\end{array}$ \\
\hline Number & 222 & 193 & 1383 \\
\hline $\begin{array}{l}\text { Self-reported VGDF exposure-ever } \\
\text { exposed }\end{array}$ & $176(79.3)$ & $110(57.0)$ & $617(44.6)$ \\
\hline Steel industry-ever exposed & $110(49.5)$ & $74(38.3)$ & $499(36.1)$ \\
\hline Combustion by-products - ever exposed & $84(37.8)$ & $58(30.1)$ & $361(26.1)$ \\
\hline Inorganic dusts or fumes-ever exposed & $130(58.6)$ & $74(38.3)$ & $471(34.1)$ \\
\hline Organic dusts - ever exposed & $60(27.0)$ & $32(16.6)$ & $196(14.2)$ \\
\hline JEM level—not exposed † & $64(28.8)$ & $92(47.7)$ & $669(48.4)$ \\
\hline JEM level-intermediate exposure & $75(33.8)$ & $61(31.6)$ & $416(30.1)$ \\
\hline JEM level—high exposure & $83(37.4)$ & $40(20.7)$ & $298(21.5)$ \\
\hline
\end{tabular}

inclusion did not alter the estimate of the effect of VGDF exposure (OR 4.1, PAR\% 2.6 to 6.3). A limited sensitivity analysis correcting for late return of the questionnaire was also carried out by introducing a dichotomous variable for late response. Addition of this new variable made no significant differences to the results as shown in table 3. For any COPD, for example, the effect of VGDF was retained at an OR of $3.9(95 \%$ CI 2.7 to 5.8 ).

Table 4 delineates the interaction between the effects of smoking in pack years (low $(\leq 20)$ versus high $(>20)$ ) and occupational exposures by calculating adjusted ORs for these effects in isolation and in combination. The overall step-up in estimated OR values, at most, approximates the product of the point estimate of each risk factor OR, a relationship numerically consistent with an additive rather than synergistic relationship, although the confidence limits for these point estimates are wide. It is evident that for any COPD the OR for low pack years alone and VGDF alone were approximately equal, and the effect of both exposures combined was more than additive. The same general pattern was seen for COPD or emphysema.

Of respondents from the community population offered spirometry, 268 (43.0\%) of those with probable COPD accepted, compared with 290 (28.1\%) of those with no airways disease. Those who underwent spirometry testing tended to be younger (mean age 67.5 compared with 70.1, $\mathrm{p}<0.001)$; men $(57.5 \%$ compared with $39.4 \%, \mathrm{p}<0.001)$; have less evidence of deprivation (mean \%IS 18.6 compared with 21.7, $\mathrm{p}=0.001$ ), be more likely to be ever smokers (59.5\% compared with $49.1 \%$, $\mathrm{p}<0.001$ ), be more likely ever to have worked in a job exposed to VGDF $(58.2 \%$ compared with $36.3 \%, \mathrm{p}<0.001)$, and have had a job classified as intermediate or high exposure likelihood by JEM assignment (51.6\% compared with $44.8 \%, p=0.009)$. The mean values for all lung function values were; forced expiratory volume in $1 \mathrm{~s}\left(\mathrm{FEV}_{1}\right) 2.20$ litres (range 0.42-4.55), forced vital capacity (FVC) 3.1 litres (range $0.9-6.0$ ), and $\mathrm{FEV}_{1} / \mathrm{FVC}$ ratio 70.9\% (range 25.8-93.1).

Table 3 Risk of COPD related to smoking and VGDF exposure



A total of 1754 people are included in the analysis shown, with complete VGDF, smoking and JEM code data.

${ }^{*}$ All ORs adjusted for age and sex. Occupational exposure-associated ORs (VGDF or JEM) adjusted for pack years of smoking. Pack years of smoking associated (continuous variable) OR adjusted for occupational exposure (VGDF or JEM) and presented per 20 pack years of exposure.

COPD, chronic obstructive pulmonary disease; JEM, job exposure matrix (944 participants classified as intermediate or high exposure); PAR, population attributable risk; VGDF, vapours, gases, dusts or fumes (874 participants exposed). 
Table 4 Smoking and occupational exposure as independent and joint associations with COPD

\begin{tabular}{|c|c|c|c|c|c|}
\hline $\begin{array}{l}\text { Cigarette smoking/occupational VGDF } \\
\text { exposure }\end{array}$ & $\mathbf{n}$ & Risk of COPD & Excess risk & Unadjusted OR & Adjusted $0 \mathrm{R}^{*}(95 \% \mathrm{CI})$ \\
\hline \multicolumn{6}{|c|}{ Any COPD, emphysema or chronic bronchitis, with or without concomitant asthma (231 cases) } \\
\hline Never/no & 530 & 0.02 & - & 1.00 & - \\
\hline Pack years low/no & 248 & 0.07 & 0.05 & 3.59 & 3.96 (1.77 to 8.89$)$ \\
\hline Pack years low/yes & 279 & 0.18 & 0.16 & 11.63 & 15.68 (7.62 to 32.28$)$ \\
\hline Pack years high/no & 186 & 0.15 & 0.13 & 8.83 & 10.44 (4.91 to 22.20 ) \\
\hline Never/no & 525 & 0.01 & - & 1.00 & - \\
\hline Never/yes & 290 & 0.04 & 0.03 & 4.10 & 5.47 (1.85 to 16.16$)$ \\
\hline Pack years low/no & 239 & 0.03 & 0.02 & 3.14 & $3.50(1.10$ to 11.18$)$ \\
\hline Pack years low/yes & 253 & 0.10 & 0.09 & 11.40 & 15.93 (5.85 to 43.34$)$ \\
\hline Pack years high/no & 180 & 0.12 & 0.11 & 13.74 & 16.47 (6.07 to 44.74$)$ \\
\hline Pack years high/yes & 320 & 0.27 & 0.26 & 38.22 & 54.11 (20.94 to 139.87 ) \\
\hline
\end{tabular}

This table includes only the 1883 respondents who gave complete smoking and VGDF data (participants with missing data for JEM classification were included). For the any COPD excluding chronic bronchitis alone analysis, those with chronic bronchitis have been completely excluded (not included with referents) to avoid misclassification bias ( $\mathrm{n}=1807$ ).

${ }^{*}$ ORs adjusted for age and sex.

JEM, job exposure matrix; pack years low, 20 pack years or less; Pack years high, more than 20; VGDF, vapours, gases, dusts or fumes.

Table 5 provides PAR\% values for COPD defined using GOLD 1 level or higher from within the subgroup of the 618 participants who underwent physiology testing (also includes supplemental population). Elevated PAR\% values are seen for VGDF exposure (20\%; $95 \%$ CI -7.2 to $40.3 \%$ ) and smoking in pack years $(45.5 \%)$. Of note, the unadjusted increased OR associated with JEM exposure is attenuated after correction for smoking, age and gender. A similar analysis to that shown in Table 5, but adjusted for the effects of smoking using a dichotomous (ever/never) smoking instead of pack years, yielded a similar OR for VGDF of 1.5 (95\% CI 0.99 to 2.3) with an associated PAR\% of 24 . Using a more restricted definition of COPD (GOLD 2 or worse), the PAR\% for the effect of VGDF exposure was estimated to be $14.0 \%$.

\section{DISCUSSION}

These findings add to the accumulating evidence supporting a causal relationship between inhaled, potentially harmful exposures at work and COPD, and indicate a high PAR\% estimate relative to a $15 \%$ median from other studies ${ }^{14} 1922$ Historically, it is likely that there have been heavy levels of VGDF exposure in this study area. A comparable investigation from
Newcastle, UK reported an occupational exposure-associated OR for COPD of 3.0 with half of the population exposed ${ }^{20}$; the PAR $\%$ extrapolated from these data is $33-50 \%$ depending on the specific formula applied, similar to our estimates. Our findings, along with those of others, suggest that a meaningful proportion of COPD could be prevented in the future by addressing harmful exposures both directly and by attenuating interactions (additive or supra-additive) with cigarette smoking.

Although the primary aim of this study was not to address the specific contribution made by steel work exposures to the development of COPD, this relationship is worthy of mention, given that Sheffield has a historic and current tradition for such industry. An earlier iron and steel foundry study identified increased symptoms and decreased airflow in foundry workers, although interpretation is complicated by concomitant pneumoconiosis and asthma. ${ }^{23}$ Iron foundry workers have a moderate (but non-significant) mortality excess for emphysema in the $\mathrm{UK}^{24}$ and in Denmark. ${ }^{25}$ The European Coal and Steel Community research programme also found a workassociated increase in chronic bronchitis, although lung function data did not show an exposure-associated $\mathrm{FEV}_{1}$ deficit. ${ }^{26}$ Other studies of steel workers have observed longitudinal declines in

Table 5 Risk of COPD related to smoking and VGDF exposure for spirometry group

\begin{tabular}{|c|c|c|c|c|}
\hline & $\begin{array}{l}\text { Unadjusted OR } \\
(95 \% \mathrm{Cl}) \text { model } 1\end{array}$ & $\begin{array}{l}\text { Adjusted OR } \\
\text { (95\% CI) model } 2\end{array}$ & $\begin{array}{l}\text { Adjusted OR } \\
\text { (95\% Cl) model } 3\end{array}$ & $\operatorname{PAR} \%(95 \% \mathrm{Cl})^{*}$ \\
\hline \multicolumn{5}{|c|}{ Spirometry alone-GOLD 1 and above (197 cases) } \\
\hline \multicolumn{5}{|l|}{ Exposure measure 1} \\
\hline 20 Pack years & 2.00 (1.67 to 2.40$)$ & 1.94 (1.61 to 2.34$)$ & $1.90(1.57$ to 2.29$)$ & 45.5 (34.7 to 54.4$)$ \\
\hline \multicolumn{5}{|l|}{ Exposure measure 2} \\
\hline \multicolumn{5}{|l|}{ JEM exposure } \\
\hline 20 Pack years & 2.00 (1.67 to 2.40$)$ & 1.94 (1.61 to 2.34$)$ & 1.96 (1.62 to 2.36$)$ & 46.4 (36.1 to 55.1$)$ \\
\hline
\end{tabular}


$\mathrm{FEV}_{1}$, but changes have been difficult to separate out from concomitant restrictive disease. ${ }^{27-29}$ Indeed, because of its prevalence and associated morbidity and mortality, silicosis rather than COPD historically has been the chief focus of nonmalignant respiratory disease research in the steel industry. ${ }^{30}$ In our study, half of those with a physician's diagnosis of COPD had worked in the steel industry, with an associated PAR\% indicating that more than 1 in 10 cases were attributable to this risk factor, even taking into account cigarette smoking. We recognise, however, that the CIs surrounding this estimate are wide and should temper the interpretation of this specific finding. Moreover, our study design does not allow further assessment of a more accurate clinical diagnosis, as no chest radiographs were available, and no other investigations to confirm or exclude asthma specifically were undertaken.

Although this study broadly supports the overall association of COPD with 'dusty trades', as well as the specific contributions to the risk of disease from certain types of exposure, the limitations of this analysis should be considered. The relatively low response rate may have introduced selection bias: although there was no sex difference between respondents and nonrespondents, non-respondents were significantly older (albeit, only a 1 year difference). Additionally, correcting analyses for later response did not significantly alter the main study findings, and the term included in the analysis to represent late response did not have a significant influence as judged by its OR. The differences in estimated associations with COPD comparing selfreported exposure (VGDF) and assigned exposure (JEM) may, in part, reflect reporting bias in the former measure, although this is counter-balanced against random misclassification biasing towards the null in the latter.

Systematic classification error in disease assignment based on subject report of a physician's diagnosis should also be considered. If such misreporting was associated with occupational exposure, this could lead to a false association between exposure and disease. Because the link between COPD and occupation (as opposed to smoking) is not generally appreciated by the lay public, this kind of systematic (as opposed to random) misclassification would not be anticipated. The weaker associations between exposure and disease in the spirometry-defined analysis, however, also warrant further discussion in this context. This sub-analysis was subject to potential further selection biases (including higher overall exposure rates), and limitations in study power. More importantly, the burden of exposure (even by JEM assignment) is such in this subset that there may be unmeasured risk in the presumed 'unexposed' referent category (including 'relatively' clean occupations in generally contaminated workplaces, as well as neighbourhoodlevel factory-driven ambient pollution). Thus, there could be multiple factors accounting for the attenuated risk estimates we observed in this lung-function-based study subset, although the elimination by spirometry-based disease classification of a false association based on systematic misreporting of physician diagnosis cannot be excluded as one possible factor. Of note, an alternative analysis of the spirometry-based subset adjusting for using ever versus never smoking rather than pack years as a continuous variable narrowed the $\mathrm{CI}$ of the OR, suggesting that how smoking is quantified and how work-related exposure is categorised can affect the estimates of occupational risk for COPD

The use of population attributable risk as an estimate of the reduction in average disease risk over a specified time interval that would be achieved by eliminating the exposures is a well applied metric in these circumstances. Definitions of PAR\% can differ among studies, however, and these statistics can be misinterpreted. We used a derivation for this value based on accurate knowledge of the proportion of cases exposed, and the adjusted relative risks associated with various risk factors. It is therefore unlikely that the PAR\% estimates are unhelpful or misleading.

In summary, this study has identified a significant contribution from workplace exposures to COPD prevalence, with a particularly heavy burden as a legacy from a highly industrialised area dominated by the steel industry. These findings must be placed into the context of cigarette smoking still being the most important overall risk factor in COPD causation, while also lending further evidence to international data showing that workplace conditions must be considered in the larger aetiological picture of this disease.

Contributors AD performed data collection, entry and analysis, coded the job exposure matrix and wrote the manuscript. DF and PB designed the study and wrote the manuscript. DF is also the study guarantor. JW designed the study, stratified participants, performed the mail out and performed spirometry, data collection and data entry. JWight contributed to the design of the study, provided access to study participants and approved the final article. CB performed job exposure matrix coding and approved the final article. CY checked the statistical analysis. VS designed and managed the secure database and assisted with mail outs. CGB performed data entry and contributed to initial study design. CathGB recruited supplemental patients, performed some spirometry and contributed to questionnaire design. All authors had access to the data if required and read the final article.

Funding The study was funded by internal research monies, and no external funding was obtained.

\section{Competing interests None.}

Ethics approval The study was approved by the Sheffield Research Ethics Committee, the Sheffield Health and Social Research Consortium and by the Sheffield Teaching Hospitals NHS Foundation Trust Research Department. All participants received written information concerning the study and gave informed consent.

Provenance and peer review Not commissioned; externally peer reviewed.

\section{REFERENCES}

1. Rabe K, Hurd S, Anzueto A, et al. Global strategy for the diagnosis, management, and prevention of chronic obstructive pulmonary disease: GOLD executive summary. Am J Respir Crit Care Med 2007;176:532-55.

2. World Health Organization. COPD. http://www.who.int/respiratory/copd/en (accessed 25 Apr 2012).

3. Murray CJ, Lopez AD. Alternative projections of mortality and disability by cause 1990-2020: Global Burden of Disease Study. Lancet 1997;349:1498-504.

4. European Lung Foundation. http://www.european-lung-foundation.org/63european-lung-foundation-elf-burden-in-europe.htm (accessed 25 Apr 2012).

5. Darkow T, Chastek BJ, Shah $\mathrm{H}$, et al. Health care costs among individuals with chronic obstructive pulmonary disease within several large, multi-state employers. J Occup Environ Med 2008:50:1130-8.

6. Halpin D, Miravitlles M. Chronic obstructive pulmonary disease: the disease and its burden to society. Proc Am Thorac Soc 2006;3:619-23.

7. Ferrer M, Alonso J, Morera J, et al. Chronic obstructive pulmonary disease stage and health-related quality of life. Ann Intern Med 1997;127:1072-9.

8. Chapman K, Mannino D, Soriano J, et al. Epidemiology and costs of chronic obstructive pulmonary disease. Eur Respir J 2006;27:188-207.

9. Greenhow E. Chronic Bronchitis Especially as Connected with Gout, Emphysema, and Diseases of the Heart. London: Longmans, 1868.

10. Greenhow EH. Report of the Medical Officer of the Privy Council. Appendix VI. London: HM Stationary Office, 1861

11. Thackrah CT. The Effects of Arts, Trades and Professions and of Civic States and Habits of Living on Health and Longevity. 2nd edn. London: Longman, 1832.

12. Fletcher C. Disability and mortality from chronic bronchitis in relation to dust exposure. AMA Arch Ind Health 1958;18:368-73.

13. Becklake $\mathbf{M}$, Dupreez $\mathrm{L}$, Lutz W. Lung function in silicosis of the Witwatersland gold miner. Am Rev Tuberc Pulm Dis 1958;77:400-12.

14. Trupin L, Earnest G, San Pedro M, et al. The occupational burden of chronic obstructive pulmonary disease. Eur Respir J 2003;22:462-9.

15. Blanc PD, Iribarren C, Trupin L, et al. Occupational exposures and the risk of COPD: dusty trades revisited. Thorax 2009;64:6-12.

16. Blanc PD, Menezes AM, Plana E, et al. Occupational exposures and COPD: an ecological analysis of international data. Eur Respir J 2009:33:298-304.

17. Hnizdo E, Sullivan PA, Bang KM, et al. Association between chronic obstructive pulmonary disease and employment by industry and occupation in the US population: a study of data from the Third National Health and Nutrition Examination Survey. Am $\checkmark$ Epidemiol 2002;156:738-46. 
18. Balmes J, Becklake M, Blanc P, et al. American Thoracic Society Statement: Occupational contribution to the burden of airway disease. Am J Respir Crit Care Med 2003;167:787-97.

19. Blanc $\mathbf{P}$, Torén K. Occupation in chronic obstructive lung disease and chronic bronchitis: an update. Int J Tuberc Lung Dis 2007;11:122-33.

20. Melville A, Pless-Mulloli T, Afolabi 0, et al. COPD prevalence and its association with occupational exposures in a general population. Eur Respir J 2010;36:488-93.

21. Fletcher CM, Elmes PC, Fairbairn AS, et al. The significance of respiratory symptoms and the diagnosis of chronic bronchitis in a working population. BMJ 1959;2:257-66

22. Blanc PD, Eisner MD, Earnest $\mathrm{G}$, et al. Further exploration of the links between occupational exposure and chronic obstructive pulmonary disease. J Occup Environ Med 2009;51:804-10.

23. Johnson A, Chan-Yeung M, MacLean $L$, et al. Respiratory abnormalities among workers in an iron and steel foundry. Br J Ind Med 1985;42:94-100.
24. Andjelkovich DA, Mathew RM, Richardson RB, et al. Mortality of iron foundry workers: I. Overall findings. J Occup Med 1990;32:529-40.

25. Hansen ES. A cohort mortality study of foundry workers. Am J Ind Med 1997:32:223-33

26. Scotti PG, Arossa W, Bugiani M, et al. Chronic bronchitis in the iron and steel industry: prevalence study. Med Lav 1989:80:123-31.

27. Wang ML, McCabe L, Hankinson JL, et al. Longitudinal and cross-sectional analyses of lung function in steelworkers. Am J Respir Crit Care Med 1996;153:1907-13.

28. Wang ML, McCabe L, Petsonk EL, et al. Weight gain and longitudinal changes in lung function in steel workers. Chest 1997;111:1526-32.

29. Kuo HW, Chang CL, Liang WM, et al. Respiratory abnormalities among male foundry workers in central Taiwan. Occup Med (Lond) 1999;49:499-505.

30. McLaughlin Al. Industrial Lung Disease of Iron and Steel Workers. London: His Majesties Stationery Office, 1950. 